Hospice care of today There for GM patients and their loved ones, from the point of diagnosis, through treatment and beyond. Out in our local communities, whether in our hospice buildings or in the places people call home, caring for patients in a truly holistic way. Developing best practice, educating and training others, and easing pressure on NHS colleagues. Always there when people need us, irrespective of post code, diagnosis or cultural background, to provide world-class, person-centred, specialist palliative and end of life care. Yet more can still be done. We are working with our system partners to influence, shape and drive evolution and future care provision for people with life-limiting illnesses in GM.

Hospice care of tomorrow Together we'll improve supportive, palliative and end of life care across Greater Manchester and East Cheshire in line with the Ambitions Framework for Palliative and End of Life Care. Our work with the GMEC Strategic Clinical Network for Palliative and End of Life Care will continue to define the standard for excellent, equitable hospice care in GM. Making sure that GM Hospices are the infrastructure that delivers those standards, aspirations and ambitions within each locality. Owning, sharing, standardising and analysing our collective data to help inform the hospice care of the future. Reaching out to even more patients and their families than ever before, whichever community they are from. Raising awareness of the importance of quality specialist palliative and EOLC and sharing our expertise with others. Our work together will help inform and support consistent, evidence-based commissioning decisions. We'll be bolder, louder and prouder - to ensure that delivering the very best holistic care for people at end of life stays at the top of the GM agenda.

\section{P-261 CREATING AN END OF LIFE CARE ACTION ALLIANCE IN SOUTHERN STAFFORDSHIRE}

${ }^{1}$ Emma Hodges, ${ }^{2}$ Richard Soulsby, ${ }^{3}$ Garry Jones, ${ }^{4}$ Marianne Grant. ${ }^{1}$ St Giles Hospice, Lichfield, UK: ${ }^{2}$ Katharine House Hospice, Stafford, UK; ${ }^{3}$ Support Staffordshire, Staffordshire, UK; ${ }^{4}$ Compton Care, Wolverhampton, UK

\subsection{6/bmispcare-2019-HUKNC.283}

Background The Staffordshire Sustainability and Transformation Partnership (STP) prioritised end-of-life care but had no plan to engage with the Voluntary (VCSE) sector. Hospices span both the healthcare system and the VCSE sector. Whilst the statutory sector can be criticised for its fragmentation and lack of engagement, the VCSE sector is extremely amorphous and lacks coherence.

Three hospices and the local voluntary sector infrastructure organisation organised two events to discuss end-of-life care with interested parties. Over fifteen organisations attended from large national charities to small local groups. These groups proposed creating a South Staffordshire End-of-Life Care Action Alliance. The STP and public health are engaging with the Alliance, whilst hospices provide a conduit between the Alliance and the STP's End-of-Life Care Board.

Initial key areas of work included:

- Raising confidence in having end-of-life care related discussions across Alliance members;

- Creating a 'community of practice' to better connect members, reducing fragmentation, and creating a shared

knowledge of community assets;
- Creating a bottom up, community development approach to care planning to demonstrate 'hard outcomes' can be achieved for the NHS.

Financial support from an NHS England VCSE Accelerator project enabled the Alliance to fast track some outcomes and activities:

- Holding a conference of circa 100 people to explore a community development approach;

- Carrying out a training needs analysis;

- Delivering 'understanding loss' workshops in several localities;

- Training in Asset Based Community Development in end of life care;

- Holding a Network Mapping workshop;

- Holding numerous discussions with groups on care planning;

- Developing a 'brand' to launch the care planning project;

- Developing a user-led care planning pilot due to launch September: known as 'flipping care plans'.

There is now in place a network of people within the VCSE community working together to improve end-of-life care. It is too early to determine the impact on the health system or delivery of tangible patient benefits, this is expected from the care planning pilot.

\section{P-262 ENGAGING WITH OUR COMMUNITY TO CREATE A NEW HOSPICE STRATEGY}

Alison Stevens, Sue Bridger. Farleigh Hospice, Chelmsford, UK

\subsection{6/bmispcare-2019-HUKNC.284}

Background Traditionally our hospice strategy was prepared by the Board of Trustees, Chief Executive and Senior Management Team.

Aim We wanted an innovative way to engage with our community to find out their ideas to help us shape a new strategic plan.

Methodology We created a strategy group made up of staff, volunteers and trustees and an idea evolved to use a Postcard campaign - 'Every Voice Matters'. We asked only one question - 'What would you like to see from the hospice in the future?'

Strategy Champions donned their strategy t-shirts delivering post-cards and post boxes to key locations including GP surgeries, leisure centres, libraries and handed them out at events to ask as many people as possible to have their say. People responded by posting cards in our boxes, by freepost, email, on our website and via Facebook or Twitter.

Results Responses were collated and key themes shared with staff and volunteers for further comments on how our new strategic plan could be delivered. All information received was then used to form a new strategic plan with four key goals:

1. Reach out;

2. Empower;

3. Invest;

4. Inspire.

Three detailed objectives were agreed for each strategic goal linking to an overarching organisational annual operational plan. 